\title{
Analysis of infrared optical polishing effluents and reduction of COD and TSS levels by Ultrafiltration and Coagulation/Flocculation
}

\author{
Isidro S Durazo-Cardenas ${ }^{12}$, Albert Noguera-Sagrera ${ }^{1}$, Susan A. Impey ${ }^{1}$ \\ Cranfield University, Cranfield, Bedfordshire, United Kingdom. MK430AL
}

Abstract

Samples of polishing effluent produced during infrared optics manufacture were analyzed. Their particle size, composition, Zeta potential, Chemical Oxygen Demand (COD), Total Suspended Solids (TSS) and Settable Solids (SetSol) were determined. Feasibility of ultra-filtration and coagulation/flocculation were investigated as treatment methods to reduce both COD and TSS.

It was found that effluents consisted of a suspension of micro and nano particles. Effluent particle size distribution reflected the removal rate of the originating polishing process. Their composition was primarily germanium and other polished substrates as well as polishing abrasives. The effluent Zeta potential was highly negative and prevented particle settling. COD of all specimens was very high; which prevented sewage discharge. Laboratory scale trials using Ultra-Filtration (UF) showed substantial COD abatement of up to $74.1 \%$. TSS was reduced to zero after UF. Comparable coagulation/flocculation COD abatement was demonstrated for the highest COD sample.

Keywords: Polishing effluents, industrial, wastewater treatment, analysis, industry, effluent

\footnotetext{
${ }^{1}$ Telephone all authors: 44(1234)750111. Email: i.s.durazocardenas@cranfield.ac.uk, albertnoguera87@gmail.com, S.A.Impey@cranfield.ac.uk

${ }^{2}$ Corresponding author
} 


\section{Introduction}

21 High value optics manufacture is an established industry in the UK. A wide range of scientific

22 and technological worldwide industries such as medical, defense and aerospace rely on these

23 precise elements.

24 Manufacture of high value optics relies heavily on polishing processes. Conventional polishing 25 employs slurries containing abrasive particles that flow between the surface being polished and

26 a pad. The slurry may have a specific $\mathrm{pH}$ to generate a slight etching of the surface that in

27 combination with the suspended abrasives removes material from the substrate [1]. Polishing of

28 optical components usually employs a series of progressively finer abrasive media to grind away

29 the higher points of a surface profile until this becomes "smooth". The different polishing stages

30 can be generally classed by the abrasive size employed. For example, larger abrasive particles,

31 of typical average of up to $45 \mu \mathrm{m}$, are used for rapid stock removal. Subsequent lapping

32 operations may employ "mid-range" abrasive sizes ranging from 14 to $6 \mu \mathrm{m}$. Final polishing is

33 typically achieved using abrasives ranging from $4.5 \mu \mathrm{m}$ to submicron. Common slurry abrasives

34 include diamond, silicon carbide, alumina and silica. Polishing slurries can be both oil, soluble or

35 emulsions.

36 Although polishing slurries can be re-circulated and are commonly reused, there is a critical

37 point where their abrasive concentration falls below optimum. At this point, polishing efficiency

38 is severely affected [2]. Consequently, these "worn" slurries are disposed and a "fresh" batch is

39 prepared. Due to the industry growth [3] and diversification [4, 5] effluent volume from optical

40 polishing is increasing and it needs to be disposed responsibly. 
41 This study focuses on the polishing effluent generated by the Infra-red (IR) optical industry. This

42 forms a substantial portion of the UK high value optics industry. The substrate materials

43 typically polished are germanium, silicon, gallium arsenide, zinc selenide, zinc sulphide, glasses

44 and other miscellaneous IR materials. Night vision systems are the most common applications of

45 these materials. Approximately 10,000 liters of wastewater are generated per year at this

46 facility by 10 dedicated machines included in this study.

47 Currently, there are a large number of publications related to disposal management of chemical

48 mechanical polishing (CMP) effluents from the semiconductor industry. Effluent disposal in the

49 photovoltaic industry has also registered a growing interest [6-9]. However, literature relating

50 to the physical or chemical properties, composition and disposal of IR polishing effluents is still

51 scarce. In this work, we set to determine the composition, particle size distribution, SetSol, COD,

52 TSS and Zeta potential of optical IR polishing effluents from "worn" slurry samples collected

53 from a major European facility. To simplify this analysis, the scope of the research has been on

54 reduction of COD and TSS within local sewage regulations. Ultra-filtration and

55 coagulation/flocculation have been initially investigated as routes to achieve this. In England

56 and Wales, sewage effluent disposal must conform to the water industry act 1991 [10]. Local

57 consent limits issued for these effluents are of 1000 and $500 \mathrm{mg} / \mathrm{l}$ for COD and TSS, respectively.

58 Other elements detailed in the consent are copper, zinc, cadmium, lead, chromium and iron. All

59 of these are limited to $2 \mathrm{mg} / \mathrm{l}$.

60

61 


\section{Experimental}

646 different waste slurry samples, A to F, were collected from a large UK Infrared specialist

65 optical polishing facility. The samples were collected at the end of 6 different production lines.

66 These polishing processes ranged from rapid material removal to final polishing for a range of

67 different substrate materials. Table 1 illustrates some of the sample characteristics noted at an

68 initial visual assessment following their collection. Table 1 also gives the polishing processes

69 originating the samples and abrasive type used.

70 Characterization of the effluent composition, particle size distribution, COD, SetSol, TSS, and

71 Zeta potential enabled specification of feasible routes for treatment. Prior to characterization

72 each sample was thoroughly homogenized by shaking it for 30 seconds before a subsample was

73 taken. This procedure was determined by initial microscopy homogenization studies.

74

75

76

77

78

79

80

81

82

\subsection{Particle size distribution and composition of polishing slurry effluents}

Characterization of the slurry particle size distribution is critical for effective treating of polishing slurries. This is even more important if treatment techniques such as ultra-filtration are to be considered. In the present work, particle size distribution was performed using Dynamic Light Scattering (DLS) techniques [11]. This was conducted in 2 stages to ensure best resolution. Initially a Mastersizer 2000 (Malvern Instruments, Worcester, UK) was used to characterize the sample solids down to $1 \mu \mathrm{m}$. Median and quantiles were calculated. After this, the particle distributions were further characterized using a Nanosizer (ZS Malvern Instruments, Worcester, 
83 UK). Prior to this, the samples were filtered to remove all particles over $1 \mu \mathrm{m}$. Each sample was

84 characterized at least three times to ensure repeatability. In addition, optical and Scanning

85 Electron Microscopy (SEM) were used to complement the DLS characterization.

86 The slurry samples were also analyzed to accurately establish their chemical composition. This

87 was conducted using both Energy Dispersive Analyses (EDS) and X-Ray Diffraction (XRD). Slurry

88 dry-powder specimens were prepared. Typically, $140 \mathrm{ml}$ subsamples of each of the slurries were

89 set in an oven at $105{ }^{\circ} \mathrm{C}$ until all fluid had evaporated leaving a dry powder. These analyses also

90 identified unexpected or hazardous residual elements that required special treatment.

$91 \quad 2.2$ Characterization of polishing effluent COD, SetSol, TSS and Zeta Potential

93 COD is a measure of the amount of oxygen used in chemical oxidation of inorganic and organic

94 matter contained in wastewater. COD together with other wastewater parameters such as TSS,

95 is widely considered an indicator of pollution degree and environmental impact. In order to

96 comply with effluent discharge regulations, wastewater effluents often require treatment to

97 abate COD and TSS prior to sewer disposal.

98 COD values were calculated for all samples using a standard procedure [12] for the examination

99 of water and wastewater. For this, the test effluent is heated up to $148{ }^{\circ} \mathrm{C}$ for $2 \mathrm{~h}$ with 100 potassium dichromate $\left(\mathrm{K}_{2} \mathrm{Cr}_{2} \mathrm{O}_{7}\right)$ and concentrated sulphuric acid $\left(\mathrm{H}_{2} \mathrm{SO}_{4}\right)$ in the presence of 101 silver (Ag) as catalyst. After cooling, the COD values were measured by photometry (NOVA 60 by 102 MERCK, Darmstadt, Germany). Results were expressed in mg/l. 
103 Settleable solids (SetSol) were measured using an Imhoff cone in accordance with standard 104 procedures [13]. One liter of each of the samples after thoroughly mixing was allowed to settle.

105 After one hour, the volume of solids $(\mathrm{ml})$ that settled at the cone apex was measured.

106 Following this procedure, the total suspended solids (TSS) was measured [14] $100 \mathrm{ml}$ of each

107 effluent sample without settleable solids were filtered using a Buchner flask and paper filter 108 with particle retention of $1.2 \mu \mathrm{m}$ (Whatman type GF/C glass-fiber, Leicester, UK). Following 109 filtration, the paper was dried at $105{ }^{\circ} \mathrm{C}$ in an oven for $2 \mathrm{~h}$. The net weight of the retained 110 particles was measured using an analytical balance to determine the TSS of each sample:

\section{Equation 1}

$$
T S S=\frac{w_{2}-w_{1}}{V}
$$

112

113 TSS total suspended solids in $\mathrm{mg} / \mathrm{l}$

114 w2 paper filter + dried suspended solids residual weight (mg)

$115 \quad w 1$ paper filter weight

$116 \quad V \quad$ volume of sample filtered (I)

117

118 Zeta potential is the electrical potential that exists at the shear plane of a particle. It describes

119 the electrostatic interactions of particles in a fluid and can be used as a measure of its

120 flocculation state. The Zeta potential was measured with a Zetasizer (Malvern Instruments,

121 Worcestershire, UK) at ambient temperature.

122 Each experiment was repeated at least twice for repeatability. 


\section{$123 \quad 2.3$ Ultra-filtration}

124 From a manufacturing point of view, ultra-filtration (UF) provides a simplified approach and 125 automation potential for efficient effluent disposal. Successful treatment of some 126 semiconductor chemical-mechanical polishing effluents using UF and reverse osmosis (RO) [15] 127 and UF preceded by chemical treatment have been previously reported [6]. UF trials were 128 conducted at laboratory scale. The cross flow filtration pressurized $\left(\mathrm{N}_{2}\right)$ system removed micro 129 and nano size particles using a porous membrane. Commercially available membranes 130 (Polyethersulfone Biomax ${ }^{\top \mathrm{M}}, \mathrm{PB}, \mathrm{MERCK}$, Darmstadt, Germany) with 67nm pore size were used.

131 These membranes were chosen based on results from the previous particle size distribution 132 measurement. The pressure was set to $0.7 \mathrm{~atm}$. as specified by the membrane manufacturer. 133 Polishing slurry subsamples of $350 \mathrm{ml}$ were filtrated. All experiments were conducted 3 times to 134 verify repeatability. Following filtration, the COD of the samples was measured to analyze the 135 effect of the filtration process.

\subsection{Coagulation/flocculation}

137 Coagulation/flocculation can be potentially a cost effective way of disposing IR polishing 138 effluents. Coagulation/flocculation is the separation of fine suspended solids brought about 139 using charge neutralization via a coagulant. Coagulation $[16,17]$ and more recently 140 electrocoagulation [18-20] have been recently employed to investigate turbidity, total organic 141 carbon (TOC) and COD abatement in semiconductor effluents. Similar techniques have been 142 applied in the photovoltaic industry [7] . 
143 The effectiveness of coagulation/flocculation was demonstrated for sample $\mathrm{F}$. This was chosen 144 because of its high COD $(6645 \mathrm{mg} / \mathrm{l})$ and $\mathrm{Z}$ potential $(-25.1 \mathrm{mV})$.

145 In order to ascertain the coagulation mechanisms of polishing effluents, initial titration tests

146 were conducted. Ferric $\mathrm{Fe}_{2}\left(\mathrm{SO}_{4}\right)_{3}$ was used as the coagulant. $\mathrm{Fe}_{2}\left(\mathrm{SO}_{4}\right)_{3}$ is widely used in 147 wastewater treatment [21] and it was readily available to the researchers. Coagulation tests 148 were undertaken on a multi-jar tester. Samples of polishing slurry effluent were dosed with 149 varying amounts of $\mathrm{Fe}_{2}\left(\mathrm{SO}_{4}\right)_{3}$ relating to different Zeta potentials. Conditions involved rapid mix 150 at $300 \mathrm{rpm}$ for 1 minute, a $15 \mathrm{~min} 30 \mathrm{rpm}$ flocculation stage and a $15 \mathrm{~min}$ settlement period $151 \quad[22]$.

\section{Results and discussion}

153 All polishing slurry samples typically had a cloudy appearance consistent with that of particles in 154 suspension. The samples color varied and this reflected particular components involved in each 155 of the polishing processes i.e. the substrate material, abrasive particles and solvents. The foam 156 reported on some of the slurry samples (see table 1 ) is attributable to aeration occurring during 157 slurry re-circulation in the polishing machine. Antifoams are commonly added to polishing 158 slurries to remedy excessive foaming that sometimes occurs. This was confirmed subsequently 159 for samples C, D and E at the optical factory shop. These antifoams may also contain oils. 160 However, a separate oily phase was not observed in any of these samples. Therefore it was 161 assumed that any oils were in emulsion. 


\section{$162 \quad 3.1$ Particle size distribution and composition}

163 Figure 1 illustrates an example of the particle size distribution of a polishing effluent F. A narrow 164 distribution around a mean of $1.15 \mu \mathrm{m}$ is observed for this sample. This is consistent with the 165 process origin of this sample being in lapping. This mean particle size is typical of a process with

166 a very low rate of material removal. In general, the particle size distribution from each of the 167 samples reflected the polishing process in which they were employed. Table 2 shows cumulative 168 particle size distribution parameters. As seen, the median particle size for polishing effluent 169 ranged from 100 to $1 \mu \mathrm{m}$ approximately. The processes with greater rates of material removal 170 yielded larger particle sizes and vice versa. Table 2 also illustrates the median and range of the

171 submicron particle size distribution for all samples. For this measurement, the effluent mean 172 particle size ranged from $460-180 \mathrm{~nm}$. Figure 2 shows the submicron particle size distribution of 173 sample F.

174 Figure 3 is a scanning electron microscope (SEM) image for sample D. A continuous layer of 175 particulate ranging from 2 to $4 \mu \mathrm{m}$ can be observed. This correlates well with the particle size 176 distribution previously obtained (Table 2).

177 Figure 4 shows a summary of the elements found in the EDS analysis conducted for each of the 178 samples. A dominant presence of Germanium (Ge) was found. This was expected as Ge was the 179 main substrate polished in most machines when the effluent samples were collected. Other 180 substrates polished in the same machines included Silicon (Si), Zinc Selenide (ZnSe) and Zinc 181 sulphide (ZnS) and these were also present in the analyses. Further elements found were 182 related to the additives present in the polishing slurry. This was confirmed by their datasheets. 
XRD analysis revealed the presence of $\mathrm{GeO}_{2}$. This was confirmed by SEM microscopy. Figure 5

184 shows an image of $\mathrm{GeO}_{2}$ nano-crystals found as precipitates in sample A. These were most likely

185 related to the abrasives used during the polishing process. Their approximate size is $500 \mathrm{~nm}$.

186 Similar nano-crystals were also found on samples B and E.

187 In addition to the polished substrates, Carbon (C) and oxygen (O) were also present as chemical

188 species in all the results. Samples A and E showed small percentages of up to $4.21 \%$ of Zinc (Zn)

189 attributable to polished substrate residuals. Iron (Fe) was present in the analysis for sample C in

190 smaller amounts of up to $0.15 \%$. This was not entirely unexpected. Metallic polishing-machine

191 tooling is often made of steel alloys.

192 In General, the EDS and XRD analysis did not return unexpected elements or compounds. These

193 analyses were clearly dominated by components relating to either to the polishing substrates or

194 the slurry abrasive used.

195 3.2 Polishing effluent COD, SetSol, TSS and Zeta Potential

196 Table 3 gives a summary of all effluents parameters calculated. The measured COD of all

197 samples as received ranged from 1789 to $6645 \mathrm{mg} / \mathrm{l}$. This was much higher than the local

198 consent limit, currently set at $1000 \mathrm{mg} / \mathrm{l}$.

199 The measured TSS values of the samples A, E and F were compliant with the current discharge 200 consent limit at $500 \mathrm{mg} / \mathrm{l}$. samples B and C, showed TSS values that were close to this limit, while 201 that of sample D was many times over this limit at $4893 \mathrm{mg} / \mathrm{l}$. These results correlated well with 202 the particle size distribution measurements previously conducted. The effluents whose 203 distribution overlapped the $1.2 \mu \mathrm{m}$ filter pore size used, had a larger number of particles filtered 
204 out and, a result a lower TSS. In contrast, sample D had a smaller submicron particle 205 distribution, and therefore a lower number of particles filtrated out. COD was re-measured 206 following the TSS procedure to observe the effect of filtration. Although a significant reduction 207 was observed for samples A and B, 54 and 55\% respectively, the new COD values remained 208 greater than current local sewer discharge consent. The COD reduction observed in effluents A 209 and B was primarily due to their particle size distribution. These samples had the largest particle 210 sizes (see table 2), with a large number of these above the $1.2 \mu \mathrm{m}$ filter pore size. In contrast for 211 samples C-F a lower COD reduction was observed. The polishing processes in which these 212 effluents originated are the finer removal stages in optical finishing. Therefore a large number 213 of particles in these effluents were in the $\mathrm{nm}$ range and meant they had a considerable 214 influence in determining the effluent COD. In view of these observations, it was confirmed that 215 ultra-filtration and coagulation/flocculation were viable treatment routes. Ultra-filtration 216 processes provide enhanced particle retention and an improved chance to abate COD and TSS 217 levels.

218 The very high negative $\mathrm{Z}$ potential values observed contributed to the low SetSol values 219 measured (Table 3). This was consistent with the initial visual assessment that reported that 220 almost or no precipitates observed. Therefore employing a settlement tank previous to effluent 221 treatment was not considered advantageous.

222 SEM sample dry preparation lead to the discovery of an oil phase in samples C, D and F. It was 223 subsequently confirmed that oil, antifoams and other additives had been used on these slurries.

224 As shown in Table 2 the samples with the higher COD had an oil phase. The effect of this oil 225 phase on the samples COD was investigated. Oils were extracted from the polishing effluents 
226 and their concentration determined using the isolute SPE columns procedure [23]. After this,

227 COD was re-measured. The extraction procedure resulted in COD improvements of 11.1, 10.4

228 and $9.7 \%$ for samples C, D and F, respectively. Oil concentration was estimated at 780 and 863

$229 \mathrm{mg} / \mathrm{l}$ for samples $\mathrm{C}$ and $\mathrm{F}$, respectively. A value for sample $\mathrm{D}$ could not be obtained, due to 230 column blockage.

\section{$231 \quad 3.3$ Ultra-filtration trials}

232 UF trials were conducted at laboratory scale using a $\mathrm{N}_{2}$ pressurized cross flow filtration system.

233 In view of the particle size distribution obtained, a $64 \mathrm{~nm}$ pore size membrane was selected for

234 all effluents. This provided economical means of operation and sufficient level of filtration for

235 most particles. Figure 6 shows the COD values for each effluent sample before and after ultra-

236 filtration. As seen there is a significant improvement for all samples. Samples A, B, C, D and F

237 showed distinctive COD improvements ranging from 60 to $75 \%$. Sample $E$, which had the lowest

238 COD at collection (1789 mg/l), observed a smaller but still favorable $34 \%$ abatement. Following

239 UF trials, samples A, B and E closely approached the current sewage discharge consent COD

240 limit at $1000 \mathrm{mg} / \mathrm{l}$. We have attributed this to the substantial removal of solids after UF, including

241 some oxidizable, as shown in the EDS and XRD analyses. Further research is necessary establish its 242 fundamental mechanism.

243 Following UF, the samples appearance was clean and transparent. Due to the level of filtration 244 used, all particles larger than $1.2 \mu \mathrm{m}$ were removed. Therefore the TSS for all samples after UF 245 was of $0 \mathrm{mg} / \mathrm{l}$, within limits set for sewage discharge consent. This was expected. The results 246 were considered an experimental validation of compliance. 
247 A similar treatment strategy was followed by Juang et.al [15]. Polishing effluents from the

248 semiconductor industry in Taiwan were treated by filtration first $(1 \mu \mathrm{m})$, followed by UF $(40 \mathrm{~nm})$.

249 Further reverse osmosis allowed the water permeate to meet tap industrial water reuse

250 standards. For photovoltaic effluents, Drouiche et al. [6] demonstrated feasibility of UF

251 preceded by chemical pretreatment for the regeneration of cutting fluids.

252 Laboratory trials have confirmed UF to be an effective method for treatment of IR effluent,

253 including samples found to have an oily phase (samples C, D and F). Permeation flux decline

254 caused by fouling and concentration-polarization effects of oils [24-26] and antifoams agents

255 [27] in metal working fluids have been previously reported. Clearly, these effects need to be

256 specifically investigated for IR effluents prior to widespread application of UF processes.

\subsection{Coagulation/Flocculation}

258 Prior to coagulation/flocculation, titration experiments were conducted to investigate the 259 relation between the amount of coagulant solution (ferric $\mathrm{Fe}_{2}\left(\mathrm{SO}_{4}\right)_{3}$ ) and the resulting zeta 260 potential of sample F. Figure 7 shows the titration curve obtained. Zeta potential (mV) was 261 plotted in relation to the volume of $\mathrm{Fe}_{2}\left(\mathrm{SO}_{4}\right)_{3}$ solution $(\mu \mathrm{l})$ used. It was observed that when the 262 coagulant solution volume exceeded $14 \mu \mathrm{l}$, larger positive $\mathrm{Z}$ potentials of over $10 \mathrm{mV}$ were 263 obtained. Conversely, when less than $4 \mu$ were used the Zeta potential was largely negative and 264 approached those of the initial sample measurements. Based on the observed behavior, a multi265 jar test was conducted. Four beakers were used with varying amounts of coagulant 266 corresponding to $\mathrm{Z}$ potentials of $-10,-5,0$ and $5 \mathrm{mV}$. SetSol, TSS and COD were re-measured 267 after coagulation/flocculation. The jar test results are shown in table 6. As seen, when a Zeta 
potential of $+5 \mathrm{mV}$ was achieved, resulted in the highest SetSol, the lowest TSS and COD. This was close to the optimum range of the Zeta potential previously observed between -11 and +3

$270 \mathrm{mV}$ using this coagulant for raw water [28]. Also, at $+5 \mathrm{mV}$, the SetSol value improved from the

271 initial 0 to $367 \mathrm{ml} / \mathrm{l}$, with a large amount of particles settling and the sample losing its

272 turbidness. The initial TSS value of sample F was already below legal discharge consent as

273 received $(153 \mathrm{mg} / \mathrm{l})$, however, this was further reduced to $51 \mathrm{mg} / \mathrm{l}$. In total, the COD was

274 reduced up to $68 \%$, from 6645 to $1980 \mathrm{mg} / \mathrm{l}$. A very similar reduction was previously obtained

275 using ultrafiltration, as shown in figure 6.

\section{$276 \quad 3.5$ Discussion summary}

277 When compared, ultrafiltration and coagulation/flocculation, they both exhibit great potential

278 for treatment of polishing effluents from the IR industry. COD improvement was virtually the 279 same. Ultrafiltration achieved a further TSS reduction, virtually of $0 \mathrm{mg} / \mathrm{l}$ as opposed to the low $28051 \mathrm{mg} / \mathrm{l}$ obtained with coagulation/flocculation. Nonetheless, this value is well under current 281 discharge consent at $500 \mathrm{mg} / \mathrm{l}$.

282 Although the COD abatement was substantial, sewage discharge consent level was not achieved 283 by either of the techniques used during this initial work. Further studies should be conducted to 284 optimize both ultrafiltration and coagulation/flocculation parameters. For example, COD 285 improvement can be potentially achieved by further particle removal via reverse osmosis, as 286 previously demonstrated by Juang et. al [15]; or chemical pretreatment as demonstrated by 287 Drouiche et al. [6]. Small scale dilution can also be applied as a simple procedure for samples A, 288 B and E, since their UF COD was very close to the sewage disposal consent. COD of these will be 
proportionally reduced to the water volume used for dilution. Evidently the main disadvantage

290 of this is the increase of the volume rate to discharge into the sewer. Nonetheless, The COD and

291 TSS improvements obtained using both UF and coagulation may potentially bring substantial

292 benefits to the environment while leading to cost effective polishing effluent disposal too.

293 Currently, disposal of these IR polishing effluents is mostly subcontracted and largely relies on

294 techniques such as high volume dilution.

295 IR optics manufacture involves a number of abrasive polishing processes and a range of 296 substrate materials. It has been found that these produce a range of effluents having different 297 composition, physical and chemical properties. As a result, characterization and disposal of the 298 IR effluents cannot be simply generalized.

299 Significant COD abatement has been achieved by the use of both ultrafiltration and 300 coagulation/flocculation. In terms of plant operational costs, ultrafiltration appears to incur the 301 highest costs compared with the simple tank process of electrocoagulation/flocculation. These 302 costs are associated with the supply of pressurized fluids, fouling, membrane replacement, etc. 303 [29]

304 It is clear from the present study that after use of UF and coagulation/flocculation there is no 305 need for large scale dilution, with reduction in the potential costs incurred and the volume of 306 effluents to be disposed.

1. Particle distribution in optical IR polishing effluents is made of a large number of particles both in the micro and nano range. Measurements performed showed the particles size 

ranged from a maximum of approximately $480 \mu \mathrm{m}$ down to a few $\mathrm{nm}$. The particle size

311 distribution was influenced by the polishing process removal rate in which the slurries were 312 used. Higher removal processes yielded larger particle sizes and vice versa.

2. The chemical composition of Optical IR polishing effluents is primarily dominated by the 314 polished substrate. Carbon and oxygen presence was also significant in the analyses. In 315 some of effluents, $\mathrm{GeO}_{2}$ abrasive nano-crystals were found. Antifoam agents and other 316 polishing slurry additives used in some of the effluents produce residual oils. These had a 317 detrimental effect on their COD.

318 3. All samples as collected had high COD values that far exceed the local sewage disposal 319 consent. The effluent Z potential was highly negative for most samples. This influenced the 320 low settleable solids and the high turbidity observed.

321 4. Ultra-filtration is a powerful process for COD abatement in polishing slurries. For all 322 polishing slurries investigated, the COD was substantially reduced. Turbidity in post $323 \quad$ ultrafiltration effluents was removed.

324 5. Coagulation/flocculation was demonstrated to be an effective process for COD reduction 325 and is comparable with ultra-filtration.

326 6. TSS were reduced to zero by the use of ultrafiltration. All particles larger than $1.2 \mu \mathrm{m}$ were $327 \quad$ filtered out. 


\section{Acknowledgements:}

329 The authors would like to acknowledge the guidance of Professor Simon Parsons and Dr Iva

330 Chianella of Cranfield University. They are also grateful for the support provided by Professor

331 Phil Irving during the manuscript preparation.

333 References:

334 [1]G. Blackman, Polished to perfection, Electro Optics, February (2011) pp. 20-22.

335 [2]H.H. Karow. Fabrication methods for precision optics, Wiley, New York, 1993.

336 [3]J. Ferry, Global trends in optical manufacturing, Optics and Photonics News, March (2012) pp. 38-43.

337 [4]A.T.H. Beaucamp, R.R. Freeman, A. Matsumoto and Y. Namba, 'Fluid jet and bonnet polishing of 338 optical moulds for application from visible to X-ray', Proc. SPIE 8126, optical manufacturing and testing 339 IX. San Diego, California, USA 08/21/11 (2011) pp. 81260U1-81260U8.

340 [5]W.I. Kordonski and D. Golini, Fundamentals of magnetorheological fluid utilization in high precision 341 finishing, J. Intell. Mater. Syst. Struct., 10 (9), (2000) pp. 683-689.

342 [6]N. Drouiche, M.W. Naceur, H. Boutoumi, N. Aitmessaoudene, R. Henniche and T. Ouslimane, 343 Assessment of the recovery of photovoltaic cells cutting fluid by chemical pretreatment and 344 ultrafiltration, Desal. Wat. Treat. 51 (2013) pp. 713-716. 
345 [7]N. Drouiche, N. Ghaffour, H. Lounici, N. Mameri, A. Maallemi and H. Mahmoudi, Electrochemical

346 treatment of chemical mechanical polishing wastewater: Removal of fluoride - sludge characteristics -

347 operating cost, Desalination, 223 (1-3), (2008) pp. 134-142.

348 [8]N. Drouiche, H. Lounici, M. Drouiche, N. Mameri and N. Ghaffour, Removal of fluoride from

349 photovoltaic wastewater by electrocoagulation and products characteristics, Desalination and Water

350 Treatment, 7 (1-3), (2009) pp. 236-241.

351 [9]N. Drouiche, F. Djouadi-Belkada, T. Ouslimane, A. Kefaifi, F. Jihane and E. Ahmetovic, Photovoltaic

352 solar cells industry wastewater treatment, Desal. Wat. Treat., 51 (31-33), (2013) pp. 5965-5973.

353 [10] The England and Wales Water Industry Act 1991. Available at:

354 http://www.legislation.gov.uk/ukpga/1991/56/contents (Accessed: 05/26/2012)

355 [11]S.K. Brar and M. Verma, Measurement of nanoparticles by light-scattering techniques, TrAC, 30 (1),

356 (2011) pp. 4-17.

357 [12] '5220 chemical oxygen demand', Standard methods for the examination of water and wastewater

$35821^{\text {st }}$ edn., American public health association, American waterworks association, Water environment

359 federation, USA, 2005, pp. 5-14-5-15.

360 [13] '2540F settleable solids', Standard methods for the examination of water and wastewater $21^{\text {st }}$ edn,

361 American public health association, American waterworks association, Water environment federation,

362 USA, 2005, pp. 2-59-2-60.

363 [14] '2540D total suspended solids', Standard methods for the examination of water and wastewater

$36421^{\text {st }}$ edn, American public health association, American waterworks association, Water environment

365 federation, USA, 2005, pp. 2-58-2-59. 

wastewater for water reuse by ultrafiltration and reverse osmosis separation, Environ. Eng. Sci., 25 (7), 368 (2008) pp. 1091-1098.

[16]C.L. Lai and S.H. Lin, Electrocoagulation of chemical mechanical polishing (CMP) wastewater from 370 semiconductor fabrication, Chem. Eng. J., 95 (1), (2003) pp. 205-211.

371 [17]C.L. Lai and S.H. Lin, Treatment of chemical mechanical polishing wastewater by electrocoagulation:

372 System performances and sludge settling characteristics, Chemosphere, 54 (3), (2004) pp. 235-242.

373 [18]C.Y. Hu, S.L. Lo, C.M. Li and W.H. Kuan, Treating chemical mechanical polishing (CMP) wastewater by 374 electro-coagulation-flotation process with surfactant, J. Hazard. Mater., 120 (1-3), (2005) pp. 15-20.

375 [19]K.T. Kin, H.S. Tang, S.F. Chan, S. Raghavan and S. Martinez, Treatment of chemical-mechanical 376 planarization wastes by electrocoagulation/electro-fenton method, IEEE Trans. Semicond. Manuf., 19 (2), 377 (2006) pp. 208-215.

378 [20]C.T. Wang and W.L. Chou, Performance of COD removal from oxide chemical mechanical polishing 379 wastewater using iron electrocoagulation, J. Environ. Sci. Heal. A, 44 (12), (2009) pp. 1289-1297.

380 [21]A.P. Sincero and G.A. Sincero, 'Coagulation', Physical-chemical treatment of water and wastewater, 381 CRC, Boca Raton, USA, 2003, pp. 545.

382 [22]S.A. Parsons and B. Jefferson. Introduction to potable water treatment processes, Blackwell 383 Publishing, Oxford, UK, 2006.

384 [23]M.J.M. Wells, D.M. Ferguson and J.C. Green, Determination of oil and grease in waste water by solid385 phase extraction, Analyst, 120 (6), (1995) pp. 1715-1721. 

[24]N. Ghaffour, M.W. Naceur, N. Drouiche and H. Mahmoudi, Use of ultrafiltration membranes in the 387 treatment of refinery wastewaters, Desal. Wat. Treat., 5 (1-3), (2009) pp. 159-166. spent cutting-oils: A review, Ind. Eng. Chem. Res., 52 (23), (2013) pp. 7603-7616.

[26]X. Hu, E. Bekassy-Molnar and G. Vatai, Study of ultrafiltration behaviour of emulsified metalworking fluids, Desalination, 149 (1-3), (2002) pp. 191-197.

[27]W.C. McGregor, J.F. Weaver and S.P. Tansey, Antifoam effects on ultrafiltration, Biotechnol, Bioeng., 31 (4), (1988) pp. 385-389. [28]E.L. Sharp, P. Jarvis, S.A. Parsons and B. Jefferson, The impact of zeta potential on the physical properties of ferric-NOM flocs, Environ. Sci. Technol., 40 (12), (2006) pp. 3934-3940. \& Eddy, $4^{\text {th }}$ edn., McGraw-Hill, USA, 2003. 
407 table legends:

408

409 Table 1- Polishing effluent samples: Visual assessment at collection, process origin and abrasive type used

410

411 Table 2- Particle size distribution by sample/process

412

413 Table 3- COD, TSS, SetSol and Zeta potential results summary

414

415 Table 4- sample $\mathrm{F}$ results after coagulation

416

417

418

419

420

421

422

423

424

425

426

427 


\section{Figure legends:}

430 Figure 1- Particle size distribution obtained using Malvern Mastersizer, sample F

431 Figure 2-Submicron particle size distribution, sample E

432 Figure 3-SEM image for sample D showing effluent particulates

433 Figure 4- Summary of elements found by sample

434 Figure 5- GeO2 nano-crystals found in sample $A$ after evaporation

435 Figure 6- COD results by sample before and after ultra-filtration and coagulation/flocculation

436 Figure 7- Titration curve for sample $\mathrm{F}$

437 
2014-01-27

\section{Analysis of infrared optical polishing effluents and reduction of COD and TSS} levels by ultrafiltration and coagulation/flocculation

\section{Durazo-Cardenas, Isidro}

Taylor \& Francis

Durazo-Cardenas, I. S., Noguera-Sagrera, A. , Impey, S. A. (2014) Analysis of infrared optical polishing effluents and reduction of COD and TSS levels by ultrafiltration and coagulation/flocculation, Desalination and Water Treatment, Vol. 52, Iss. 25-27, pp. 4612-4621 https://cris.cranfield.ac.uk/converis/mypages/editor/Publication/4233055/default Downloaded from Cranfield Library Services E-Repository 